\title{
Exploring the intrinsic indicators of individual resiliency
}

Orio, Terrezyl Ramon $\varangle$

Department of Psychology, San Carlos University, Cebu, Philippines (terrezyl@yahoo.com)

\section{Abstract}

This paper aimed to identify the intrinsic indicators of individual resiliency. It tried to find innate or inherent capacities and traits of Cebuanos as signs of coping effectively from the typhoon experience. There were eleven female, adult, Cebuano typhoon Haiyan survivors from Madridejos and Medellin, Cebu, who volunteered as participants. Focus group discussion yielded four main themes namely optimism, sense of coherence, hardiness, and religiosity/spirituality coping. Each main theme had its corresponding sub-themes. Being hopeful, being grateful, positive thinking, exerting efforts to stand up again, and striving hard to survive were the sub-themes of optimism. Sense of coherence was composed of helping each other and using available resources to rebuild or repair damaged houses. Hardiness was revealed through taking courage, enduring, remaining strong for self and family. Lastly, religiosity/spirituality coping was shown through praying to God, having faith in God, and believing in God's mercy. Optimism, sense of coherence, hardiness, and religiosity/spirituality coping were the indicators of Cebuanos' resilience. These indicators are beneficial in developing a program that serves to nurture the resiliency of individuals.

Keywords: resiliency; optimism; religion; Cebu; Philippines 


\section{Exploring the intrinsic indicators of individual resiliency}

\section{Introduction}

"The world breaks everyone and afterwards many are strong at the broken places".

- Ernest Hemingway -

For years, Philippines has been challenged by different adversities especially matters pertaining to natural calamities such as typhoons and earthquakes. However, despite the susceptibility of the country to experience different calamities and also the number of times the country had experienced them, Filipinos are still known for being resilient. The recent typhoon named Yolanda that struck the country last November 8, 2013 which left a devastating effect to the entire nation especially to people who were directly affected. The typhoon affected 16.1 million people across the nine regions. It was reported that 6,201 fatalities and 1,787 persons missing and a total of 1.1 million houses were damaged which close to 551,000 were totally destroyed (The World Federation, 2014). Survivors of Yolanda have lost mostly everything they have in their lives such as homes, jobs, resources, and loved ones. One can simply ask, with the severe damaged it inflicted to them, and how did the Filipinos especially the Cebuano survivors bounce back from the tragedy?

Filipinos can still carry to smile and make jokes despite the difficult situations. Filipinos can still instill hope even to the hopeless times. Filipinos have great faith which makes them typhoon proof or calamity proof. Humor, hopeful, faith in God, are these signs indicative of Filipinos resiliency, specifically Cebuanos' resiliency?

This study explored the intrinsic indicators of Cebuano's resiliency. Also, it aimed to describe the conditions of Yolanda survivors months after the event, identify aspects of the lives of Yolanda survivors that contribute to their resilience and delineate understanding of the term resilience from the perspectives of Cebuano survivors of Yolanda. The researcher identified the internal characteristics, traits, innate capacities of the survivors which helped them in bouncing back and coping effectively from the struggles brought by typhoon Yolanda. It was the hope of this study to uncover a unique pattern of resiliency from the Cebuano survivors which can be basis for future studies in proposing a program to nurture resiliency among Cebuanos.

\section{Review of Related Literature}

Different studies have been done about understanding the concept of resilience. However, up to now, researchers have not arrived yet a consensus of the meaning of the word (Khanlou \& Wray, 2014). The term resilience is oftentimes regarded in different studies as a developmental outcome, set of competencies, and coping strategies (Kirby \& Fraser, 1997). But the most common idea of resilience especially in the field of mental health is its association to good outcome after experiencing adversities (Masten, 2001). In fact, Masten and Powell (2003) said that "resilience refers to patterns of positive adaptation in the context of significant risk or adversity" (p. 4). However, a great deal of scholars assert the importance of the cultural beliefs, behaviors, and practices exclusive to population when understanding resilience (Mattis, 2004; Utsey et al., 2007). There are evidences that show the association of cultural beliefs, behaviors, and practices of Africans and Americans to effective coping mechanisms (Taylor, Chatters, \& Levin, 2004; Utsey, Adams, \& Bolden, 2000). Gilligan (2004) also point out that resilience is now regarded as a variable quality that evolves from repeated interactions between a person and its surroundings.

On the other hand, the concept of resilience has been applied in a variety of settings for example psychology, psychiatry, ecology, social science, economy, and engineering, for several decades (Renschler et al., 2010, Rose, 2009). It has received an increasing amount of attention in the area of risk management over the past several 
years. In the case of natural and man-made threats, analyses of resilience have focused on critical infrastructures, communities, and regions and on the resilience of various subsystems like a community's or region's economy, governmental units, emergency services sector, and the civilian population. For example, the support and help the disaster survivors received from each other served as significant factors that foster resilience (Fernando \& Herbert, 2011). Resilience is also consistently found to be a predictor of less development of post-traumatic stress disorder (Bonnano, Galea, Bucciarelli, \& Vlahov, 2006).

Other definitions of resilience can be considered which focus on what happens "after the adverse event" (i.e., an adverse natural or man-made event), whereas others include one or more "before the adverse event" components, including resistance, protection, anticipation, and preparedness.

It is quite obvious therefore that resilience has been defined in varied ways. But the following definitions capture the heart of the researcher of this study.

Resilience is the ability to "bounce back" and cope effectively in the face of difficulties", "bend, but not break under extreme stress", "rebound from adversities", "handle setbacks, persevere and adapt even when things go awry", "maintain equilibrium following highly aversive events". It is also the ability to learn to live with ongoing fear and uncertainty, the ability to show positive adaptation in spite of significant life adversities and the ability to adapt to difficult and challenging life experiences (Masten \& Reed, 2002, p. 228).

As being defined above, resilience can be further explored and studied through contemporary models. Amid the growing studies regarding resilience after adverse events such as disasters, further exploring resilience of disaster survivors through contemporary models employed in the present study may provide interesting insights. Furthermore, looking into the resilience of Filipinos, who are mostly religious (Abad, 2001), may also provide interesting insights on some unique Filipino patterns of resilience.

Two theoretical models from a psychoanalytic perspective and contemporary models can be used to extract intrinsic indicators of individual resilience. Contemporary models discuss resilient functioning as being a trait or personality characteristic. These include the construct of optimism, Antonovosky's sense of coherence model, Kobasa's model of hardiness, and religiosity/spirituality coping.

\subsection{Optimism}

Optimism can be simply defined as expecting good things to happen. Optimists have been described as individuals who expect good things to happen to them as opposed to pessimists who expect bad things to happen to them (Carver \& Scheier, 2002). Optimists are reported to have different expectancies in that they tend to believe that stress and adversity can be successfully managed and this is believed to have a positive influence on their approach to coping with adversity, and their overall resilience. Strategies and behaviors that have been identified as characteristic to optimists include confidence and continued effort exerted in dealing with adversity, adopting a planful and problem focused approach particularly if the stress is controllable, the use of positive reframing and searching for benefits if the situation is uncontrollable, an acceptance of the reality of difficult situations, retaining self-control and remaining self-directed, and not focusing on distress and physical symptoms. In general optimists tend to use approach coping as compared to pessimists who tend to use avoidant coping (Carver \& Scheier, 2002).

An extensive body of literature supports the view that optimists tend to experience less distress than those of a pessimistic nature, and that they maintain a healthier level of psychological well-being (Carver \& Scheier, 2002; Schneider, 2001). It has been suggested by some theorists, however, that optimism may not be the most useful or adaptive strategy in particular situations (as reported by Schneider, 2001; Carver \& Scheier, 2002). Optimism can be seen as wishful thinking that distracts one from making plans and achieving goals, as ignoring or underestimating a threat, as precluding one from caution, reservation and the conservation of one's resources 
when necessary (Peterson, 2000). In response to this criticism is that realistic optimism has to be emphasized. This involves hope and aspiration towards positive experience at the same time acknowledging what we do not, and cannot know. In periods of uncertainty, the realistic optimist will hope and work towards desired outcomes, and focus on the potential within the situational constraints (Schneider, 2002).

\subsection{Sense of Coherence}

Antonovosky developed the sense of coherence model following his observation that a significant number (29\%) of women survivors from the concentration camps of World War II retained good emotional health (Frankenhoff, 1998). He identified health as being the capacity to adapt to stressful situations, and as having a dynamic nature on the continuum between ease and dis-ease. Antonovosky hypothesized that the changing position of a person's health status was determined by the capacity to manage the tension of ever-present stressors through the application of cognitive and emotional resources that involve both coping and social support (Frankenhoff, 1998). He recognized that stressors have the potential to lead to system chaos or entropy, and focused on the balanced management of the tension produced to prevent biopsychosocial burden (Frankehoff, 1998). Sense of coherence was viewed as a life development process that becomes "dynamically stabilized" during the first three decades of life and as remaining relatively the same from this time on (Frankenhoff, 1998).

Sense of coherence, as defined by Antonovosky, is a "global orientation that expresses the extent to which one has a pervasive, enduring though dynamic sense of confidence" that (1) the stimuli we experience from both our internal and external worlds are structured, predictable and explicable, (2) that we have the resources available to meet the demands of these stimuli, and (3) that these demands are worthy of both the investment and the engagement (Antonovosky, 1987, p. 19).

Antonovosky developed his theory on the basis of research interviews involving 51 subjects who had all experienced major trauma and had been reported as coping remarkably well. Following analysis of the interviews he classified 16 of the subjects into a group with a strong sense of coherence and 11 with a low sense of coherence. He then searched the interview protocols for themes that were evident in one group and absent in the other. As a result he identified three themes that reflected a strong sense of coherence; comprehensibility, manageability and meaningfulness (Antonovosky, 1987; Frankenhoff, 1998).

Comprehensibility was defined by Antonovosky as being the extent to which one perceives the stimuli confronting one in the environment as making cognitive sense. This means that the information that confronts one is ordered, consistent, structured and clear as opposed to noise-chaotic, random, disordered, accidental or inexplicable. The individual who is high on this factor expects stimuli to be predictable, and if not that it can be ordered and explicable. The second component, manageability, is defined as the extent to which an individual perceives that they have the resources available to meet the demands as being under one's control, or under the legitimate control of others. An individual high on manageability will not feel as though they are victimized by others or that life is unfair. They accept that adverse events do occur but that one will be able to cope and that the consequences will be bearable. The third component of meaningfulness, the motivational element, relates to the position that certain areas of life are important in terms of both the cognitive and emotional sense. It relates to the sense that at least some of the demands of life are worth investing in and worthy of commitment. Challenges are perceived as welcome as opposed to burdensome, and that engagement is worthwhile (Antonovosky, 1987).

Antonovosky suggests that all three components are interrelated and necessary but that there may also be unequal centrality. He deemed meaningfulness to be the most essential as without this the other two components are likely to be temporary. Following meaningfulness, Anotonvosky believed comprehensibility to be the next important with high manageability contingent to understanding the situation. In saying this however, Anotnovosky also believed manageability to be important given the hypothesis that if one does not believe that one has the necessary resources at one's disposal then meaningfulness will be lessened and coping efforts 
diminished (Antonovosky, 1987). The defining characteristic of a person with a high sense of coherence is the ability to choose what appears to be the most appropriate strategy among the resources available.

Antonovosky states that one's sense of coherence is a "generalized, long lasting way of seeing the world and one's life in it" (Antonovosky, 1987, p. 22). In saying this he does not claim that sense of coherence is infinite and reports that the individuals interviewed set boundaries and limits as to the spheres of life that were important to them. Sense of coherence is reportedly built up by life experiences that confirm the belief that life in general is comprehensible, manageable and meaningful.

\subsection{Hardiness}

Hardiness was a construct developed by Kobasa in the 1970s as a means to explain psychosocial characteristics moderating the stress-illness relationship and stress resilience (Funk, 1992; Wiebe \& Williams, 1992). It has been described as a motivating factor that enables the resolution of stressful situations and adapting to health problems (Pollock, 1989), and to be a distinct personality structure of those who experience high levels of stress but remain healthy (Jennings \& Staggers, 1994). Two major premises from existential theory are pertinent to hardiness and underpin the nature of the construct. Firstly, personality is viewed as a dynamic actively constructed process and that although life is always stressful this stress can be turned into positive opportunities for growth. Secondly, hardiness is believed to be an aggregate of three factors that comprise cognitive and behavioural processes that buffer stressful events and the way in which the individual perceives them (Tartasky, 1993; Wiebe \& Williams, 1993).

The three factors alluded to above include commitment, control and challenge (Funk, 1992; Tartasky, 1993; Wiebe \& Williams, 1992). Commitment is related to the ability to believe in the importance and value of who one is, the activities one is involved with, and one's involvement in life in general. It is believed to provide a sense of purpose with which to face stressful life events, and to diminish the perceived threat in doing so. The control factor is related to the tendency to believe and to act as though one can influence events, and to seek explanations as to what has happened. It is proposed that this can allow people to believe that they can alter the course of events and manipulate stressors. The factor of challenge is based within the belief that the environment is forever changing and that this provides opportunities for personal growth as opposed to feelings of threat and insecurity. This allows hardy people to welcome challenge and use it as a resource to cope with stress (Tartasky, 1993). The construct infers that individuals identified as hardy experience the same number of stressful life events but that the presence of hardiness diminishes their impact (Wiebe \& Williams, 1992). Hardiness is also believed to assist the coping response through eliciting appropriate social support (Funk, 1992).

A significant amount of research has been done on hardiness with various population groups with the construct of hardiness examined in relation to health concerns, physiological reactivity, optimism, mood symptoms, burn out, neuroticism and noise induced stress (Funk, 1992). Results have found that hardy individuals use more positive self-statements than others (Allred \& Smith, 1989, as cited in Tartasky, 1993); that hardiness is associated with reduced use of regressive coping, and that high hardy individuals make less threatening appraisals of stressors.

\subsection{Religiosity/Spirituality Coping}

Spirituality and religion are complex phenomena and multidimensional in nature. As we explore religiosity and spirituality, there is a need to differentiate each construct. Religion signifies a bond between humanity and some greater-than-human power. It involves a supernatural power to which individuals are motivated or committed, a feeling present in the individual who conceives such a power and ritual acts carried out in respect of that power (Wulff, 1997). On the other hand, spirituality can be understood as thoughts and practice either broadly or narrowly conceived, one's relationship with ecology or nature, human achievement or potential (Spilka, 1993) . Spirituality as a multidimensional constructs same as religion has six components (LaPierre, 
1994). These are search for meaning in life, an encounter with the transcendence, a sense of community, search for the ultimate truth or highest value, a respect and appreciation for the mystery of creation, and personal transformation.

Empirical reality is that most people experience spirituality within an organized religious context and fail to see the distinction within these phenomena (Marler \& Hadaway, 2002). Religiosity and spirituality are said to be related constructs. Spirituality and religiosity are substantively related to each other, as both are connected to the idea of the sacred (Pargament, 1997). Spirituality can be understood as a search for the sacred, a process through which people seek to discover, hold on to, and, when necessary, transform whatever they hold sacred in their lives (Pargament, 1997, 1999). This search for the sacred takes place in a larger religious context, one that may be traditional or nontraditional (Hill et al., 2000). The sacred includes concepts of God, the divine, ultimate reality, and the transcendent as well as many aspect of life that takes an extraordinary character by virtue of its association with or representation of such concepts (Pargament, 1999). The sacred is common denominator of religious and spiritual life. It represents the most vital destination sought by the religious/spiritual person, and it is interwoven into the pathways many people take in life.

Religiosity/Spirituality has been recognized as having important relationships with mental health status. R/S has been shown to be effective in coping with disability, illness, and negative life events (Pargament, 1997). Prayer can be an effective coping mechanism (Poloma \& Pendleton, 1989). Religion and spirituality can also emerge at the points of cognitive appraisal and coping. Individuals can mobilize a variety of $\mathrm{R} / \mathrm{S}$ coping strategies that can be public (e.g., religious service attendance), private (e.g., prayer) or non-traditional (e.g., meditation) in nature (Harrison, Koenig, Hays, Eme Akwari, \& Pargament, 2001). For example, prayer functions in multiple ways (Bade \& Cook, 2008) and can be effective at many levels in dealing with crises (McCullough \& Larson, 1999). People also call on various forms of R/S support when faced with stressful events (Koenig \& Larson, 2001). They may cultivate an attachment bond with a higher power, or they may pursue spiritual connections with nature (Burkhardt, 1994) and other people such as clergy (Weaver, Koenig, \& Larson, 1997). $\mathrm{R} / \mathrm{S}$ support predicts positive health factors such as lower morbidity for hypertension (Ferraro \& Koch, 1994) while a lack of religious involvement predicts problems such as higher mortality rates (Oman \& Reed, 1998).

Highly religious individuals often rely on R/S strategies to cope with stress. Meisenhelder and Marcum (2004) reported that $92 \%$ of their sample of Presbyterian clergy turned to God for support after the terrorist attacks of $9 / 11$. Yet R/S coping are by no means limited to the highly religious. For example, family members of homicide victims (Thompson \& Vardaman, 1997), bereaved parents (Brotherson \& Soderquist, 2002), and female survivors of domestic abuse, (Gillum, Sullivan, \& Bybee, 2006) turn to R/S as a main means of coping. $\mathrm{R} / \mathrm{S}$ coping has consistently emerged as a resource to help people cope with physical illness and disability (Gordon et al., 2002) especially life-threatening illness such as end-stage pulmonary disease (Burker, Evon, Sedway, \& Egan, 2005) and HIV/AIDS (Baesler, Derlega, Winstead, \& Barbee, 2003). R/S coping is also a common strategy for those facing mental health issues (Bhui, King, Dein, \& O'Connor, 2008) including severe disorders such as schizophrenia (Awara \& Fasey, 2008).

Despite its wide spread use, researchers should take note that a reliance on $\mathrm{R} / \mathrm{S}$ coping may be culture specific. For example, R/S may not be central to coping for those who are less traditionally religious, such as those from European culture as compared to North American culture (Stifoss-Hanssen, 1999). Indeed, research has shown that certain groups rely on religious coping more than others, including older adults (Bergan \& McConatha, 2001), African Americans and women (Levin, Taylor, \& Chatters, 1994), the disabled (Johnstone, Glass, \& Oliver, 2007) widowed individuals (Roff, Durkin, Sun, \& Klemmack, 2007) and majority of Filipinos. For Filipinos, religiosity or spirituality is an effective coping strategy.

The Filipino's resilience and adaptability have been tested throughout history. Recently, the most destructive earthquake in memory struck Northern Luzon and Bohol, followed by a killer typhoon Yolanda which paralyzed booming Tacloban City and Cebu. After 600 years of inactivity, Mt. Pinatubo erupted, burying cities and towns 
while flash floods washed away Ormoc, Leyte. Despite these disasters, the Filipino, though bent, remained unbroken. As Estanislao (2001, p. 104) mentions, “... the perception remains that Filipinos are indeed one of the happiest people in the world. Andres (1989, p. 12) even asserts, "The Filipino can maintain his patience and endurance in the face of adversity. To what then do we attribute the perception of the Filipino's undying resiliency? This question gives credence to a nation's strength of character and its peoples' courage. Resiliency is the unsung note that characterizes the strength of a great people. As Andres (1989, p. 12) mentions, "Filipino's resiliency helps to maintain his good-naturedness and good sense and ability to achieve a measure of recovery and progress under the most discouraging barriers."

In summary, the concepts on optimism, sense of coherence, hardiness, and religiosity/spirituality coping may offer factors indicative of resilience. Resilience is believed to be dynamic yet enduring over time, and there is potential within some of the models for the development of resilience to evolve with experience. Thus, these may be used in identifying and exploring the intrinsic indicators of Cebuanos' resiliency, which is the main aim of this study.

\section{Methodology}

\subsection{Research Design}

The study used qualitative research design. Focus Group Discussion was utilized to gather data. Thematic analysis was used for data analysis. Through thematic analysis, main themes and its corresponding sub-themes were extracted.

\subsection{Research Respondents}

The participants were adult survivors of typhoon Yolanda situated in Northern areas of Cebu like Medellin and Mancilang, Madridejos. The participants were chosen using purposive sampling. There were eleven (11) female adult survivors who volunteered to be participants of this study. There were seven female adult survivors from Mancilang, Madridejos and four female adult survivors from Medellin.

\subsection{Research Environment}

Focus group discussion was conducted at Medellin and Mancilang, Madridejos, a municipality in Bantayan Island. Bantayan Island is one of the most affected areas hit by Super Typhoon Yolanda. The island which is considered as the "Egg Basket of the Visayas" with more than 1.1 million egg productions distributed in various parts of Visayas and Mindanao suffered with an estimated of more than $90 \%$ total damage.

Medellin is one of the badly hit areas in Northern Cebu (http://www.philstar.com/opinion/2013/11/12/1255743/northern-cebu-just-badly-hit-leyte). In Medellin, around $90 \%$ of houses are partially or totally damaged, estimated its mayor Ricardo Ramirez (http://www.rappler.com/nation/43319-cebu-municipalities-isolated).

\subsection{Research Procedure}

A Psychosocial Support team from University of San Carlos spearheaded by the Political Science Department, together with the Psychology Department, went to Mancilang, Madridejos to give Psychosocial Support sessions to children, adolescents and adults. After the session with the adults, the researchers were asking volunteers from the group to be the part of the focus group discussion. The researcher gathered the volunteers to orient them of what to do during focus group discussion. The volunteers were given informed consent form and let them sign it as confirmation that they agreed to be part of the study. The discussion started with establishing rapport by introducing one by one and asking the participants how they were at that time. The 
researcher asked this question, "Kumusta naman mo?", as a discussion starter. The second question asked was, "What have you done to bounce back or cope with from the disaster Yolanda? in Cebuano version, "Unsa man ang imong gihimo para makabangon ka gikan sa katong bagyong Yolanda?" One by one they answered the question. The discussion ended with a summary done by the researcher. Incentives were given. The whole discussion was audio recorded as per approval from the participants.

Another Psychosocial Support team composed of peer facilitators, religious people and counselors from the Franciscan Sisters Pro Infante Et Familia Community went to Medellin to give psychosocial sessions to children, adolescents and adults. The researcher was part of the team. The same procedure was given to the participants in Medellin.

\subsection{Data Analysis}

A focus group discussion (FGD) was utilized to gather data. The data gathered was audio recorded. FGD is a good way to gather together people from similar backgrounds or experiences to discuss a specific topic of interest. The group of participants is guided by a moderator (or group facilitator) who introduces topics for discussion and helps the group to participate in a lively and natural discussion.

Thematic analysis was used to analyze the data. Thematic analysis is the most common form of analysis in qualitative research. It emphasizes pinpointing, examining, and recording patterns (or "themes") within data. Themes are patterns across data sets that are important to the description of a phenomenon and are associated to a specific research question. The themes become the categories for analysis. Thematic analysis is performed through the process of coding in six phases to create established, meaningful patterns. These phases are: familiarization with data- transcribing data, reading and rereading the data, noting down initial ideas; generating initial codes -coding interesting features of the data in a systematic fashion across the entire data set, collating data relevant to each code; searching for themes among codes- collating codes into potential themes, gathering all data relevant to each potential theme; reviewing themes- checking in the themes work in relation to the coded extracts (level 1) and the entire data set (level 2), generating a thematic map of the analysis; defining and naming themes- ongoing analysis to refine the specifics of each theme, and the overall story the analysis tells, generating clear definitions and names for each theme; and producing the final report- selection of vivid, compelling extract examples, final analysis of selected extracts, relating back of the analysis to the research question and literature, producing a scholarly report of the analysis (Braun \& Clarke, 2006).

In this study, the researcher used thematic analysis as a qualitative method utilizing positivist/essentialist lens and deductive way of analyzing data. The analysis was driven by the researcher's theoretical or analytic interest in the area, and was more explicitly analyst-driven. This form of thematic analysis provided more a detailed analysis of some aspect of the data and tried to fit in to the pre-existing model or frame.

The researcher followed criteria for good thematic analysis (Braun \& Clarke, 2006) in order to achieve validity and reliability of the results. First, in the transcription process, the data had been transcribed to an appropriate level of detail, and the transcripts were checked against the tapes for accuracy. Second, during coding, each data item had been given equal attention in the coding process, themes had not been generated from a few vivid examples but instead the coding process had been thorough, inclusive and comprehensive, all relevant extracts for all each theme had been collated, themes had been checked against each other and back to the original data set, themes were internally coherent, consistent, and distinctive. Third, in the analysis process, data had been analyzed - interpreted, made sense of - rather than just paraphrased or described, analysis and data matched each other - the extracts illustrated the analytic claims, analysis showed a convincing and well-organized story about the data and topic, and a good balance between analytic narrative and illustrative extracts was provided. Overall, enough time had been allocated to complete all phases of the analysis adequately, without rushing a phase or giving it a once-over-lightly. 


\section{Results}

This paper aimed to identify the intrinsic indicators of Cebuano's resiliency. With the use of thematic analysis, there were four main themes with its corresponding sub-themes emerged. The themes are clearly displayed through the use of thematic map below.

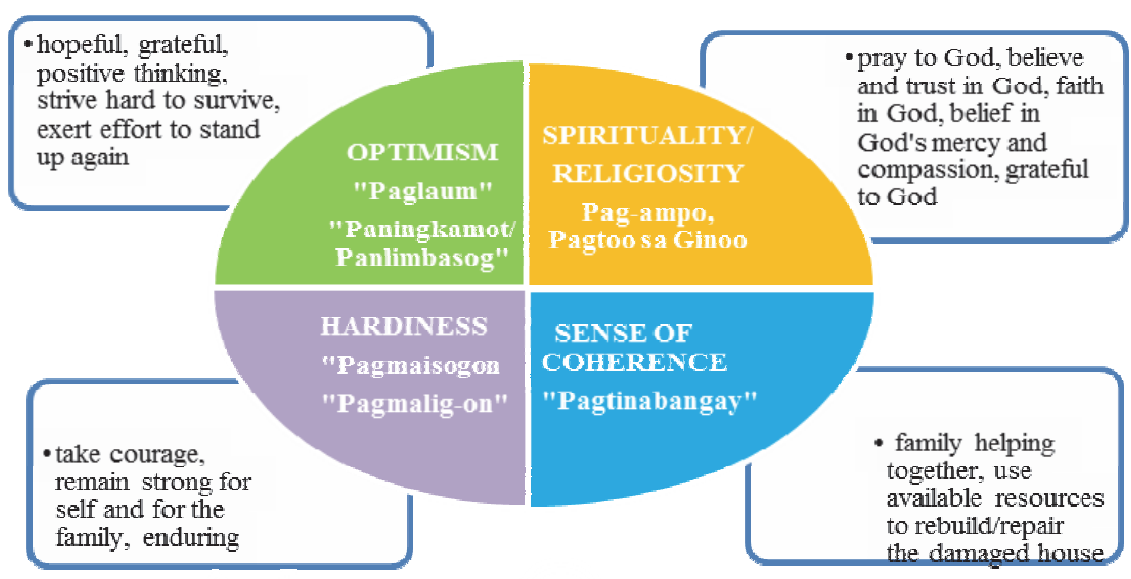

Figure 1. Thematic map showing the main themes and its corresponding sub-themes

The main themes were said to be the main intrinsic indicators of resilience of the participants. The four main themes were optimism, hardiness, sense of coherence and religiosity/spirituality coping. Based from the extracted main themes, there were corresponding sub-themes. The themes are supported by examples of raw responses from the survivors and its corresponding code (name of survivor, box number, place/setting of the focus group discussion).

In optimism, "Paglaum" or sense of hope/hopeful and "Paningkamot" or striving/exerting effort were evident. Optimism was shown through being hopeful, being grateful, positive thinking, striving hard/exerting efforts to survive and stand up again. Striving hard and exerting efforts were shown through doing gardening, planting vegetables, fishing, selling, husband and son working, taking care of children. These could be understood from the responses of the participants. There were some survivors who were hopeful and positive despite of the struggles. Like Merly, she said that there is a need to put hope in oneself and to have positive thinking.

"Paglaum sa kaugalingon, ug positibo sa huna-huna" (Hope in oneself, and positive thinking). (Merly, B261, Madridejos).

Shiela mentioned to not lose hope.

“Ayaw kawad-i sa paglaum...” (Not losing hope). (Shiela, B301, Madridejos).

Striving hard or exerting efforts to survive were evident in the responses of Pat and Nida. Pat said,

"Paningkamot nga makasurvive jud mi...." (We strive hard to survive). (Pat, B14, Madridejos).

Nida told the group that she needs to exert much effort for a living like gardening, planting vegetables, selling...,

"Magpanisikay-sikay sad sa pagpanginabuhi...,. mag-garden sa palibot,......., magtanum ug batong, sili, ug gulay...., makabaligya para mkapalit ug bugas" (Exerting more effort to earn a living, gardening in the backyard, planting vegetables, selling in order to buy rice). (Nida, B20,B26, B32, Medellin). 
Part of optimism was being happy and grateful of the help received from the non-government agencies and local government units. As Wilma and Marites shared,

"May gali naay mga hinabang sa amoa nga gikan sa Christ for Asia" (It is good that we receive help from Christ for Asia). (Wilma, B63 Madridejos); “.. unya malipay mi kung ang barangay moannounce nga naay ipanghatag.... mopakpak gyud among dunggan mam"(We feel happy if we hear announcement from the barangay that there is help to be given). (Marites, B158, B159, Medellin).

The second main theme was sense of coherence. The sub-themes of sense of coherence were "Pagtinabangay", which means helping each other, and the using of available resources in order to repair/rebuild damaged houses. It was revealed in the sharing of the participants that they were able to bounce back from the struggling experience from typhoon Yolanda through family members helping each other. As Zenaida mentioned,

"Sa akong nabuhat kay pagtabang nako sa ako bana..." (What I have done was I helped my husband). (Zenaida, B244, Madridejos).

Same with Miriam, her husband went fishing and she helped in selling the fishes,

"Nanggawas ang mga bangus, pagpamukot sa akong bana...ug ako tabang baligya” (My husband went fishing milk fish, I helped in selling). (Miriam, B273, Madridejos).

There were participants who were using available resources so that they could repair/rebuild damaged houses. Nene shared that her husband cut trees and used the woods for support posts, and used bamboo sticks for their rest area,

"Ako bana kabalo man, nagputol dayon ug kahoy ug nagpabarug ug haligi, ang mga kawayan, gimaniho para naay kahigdaan." (My husband cut woods and made use of it for posts and walls in rebuilding our house, and the bamboos were used for our rest area/beds), (Nene, B102,Medellin), “...akong bana, tabang mi ug ayuda”. (Nene, B120, Medellin).

Thirdly, hardiness was composed of "Pagmaisugon" and "Pagmalig-on" which meant take courage, remain strong and endure. The participants remained strong in heart and mind for themselves and for their families. Merly stated that being weak would not help her,

"Giibanan ang kaguol kay wala may makatabang sa kaugalingon kita ra man, di man makatabang kung magpaluya2x" (Lessen the feeling of sadness because nobody can help us except us only, and being weak doesn't help). (Merly, B255, Madridejos).

In addition, Nene made ways to gain energy and endurance after the typhoon,

"Nagpalagsik, human sa katalagman nga nahiaguman" (Energized oneself after the typhoon experience). (Nene, B79, Medellin).

Finally, religiosity/spirituality was the participants' another way of coping from the difficulty. They prayed to God- " pag ampo sa Ginoo", trusted God - "pagsalig sa Ginoo", had faith in God- "pagtoo sa Ginoo", and believed in God's mercy. Many of the participants expressed their belief in God's mercy. Like Miriam, she talked that God's mercy saved them from death and helped them stand up or bounced back,

“Kaluoy-an gyud intawn sa Ginoo nga walay namatay namo”...” Kaluoy sa Ginoo, nakabangon ra” (With God's mercy, no one of us died......with God's mercy, we are able to stand up). (Miriam, B106, B110, Madridejos).

It was essential to mention the sharings of Wilma and Miriam. They prayed to God, 
"Nagsige nako pangamuyo sa Ginoo ......" (I always ask help from God). (Wilma, B51, Madridejos), "Nag ampo inatwn mi.." (We prayed ....). (Miriam, B84, Madridejos).

\section{Discussion}

The stories from the participants revealed their conditions months after the typhoon Yolanda. Based from their statements, it identified aspects of their lives that contributed to their resilience. The results delineated our understanding of the term resilience from the perspectives of Cebuano survivors of Yolanda. The results of the study showed that there were four main themes extracted from the data analysis. These were optimism, sense of coherence, hardiness, and religiosity/spirituality coping. The main themes were clearly manifested from the responses of the participants. These four main themes were the indicators of Cebuano's resilience.

The first indicator of Cebuano's resilience was optimism. This was revealed through being hopeful, being grateful, thinking positive, striving hard/exerting efforts to survive and stand up again. Striving hard and exerting efforts were shown in doing gardening, planting vegetables, fishing, selling. Optimism can be simply defined as expecting good things to happen despite the difficulty. Optimists have been described as individuals who expect good things to happen to them (Carver \& Scheier, 2002). Optimists tend to believe that stress and adversity can be successfully managed and this is believed to have a positive influence on their approach to coping with adversity, and their overall resilience. Strategies and behaviors that have been identified as characteristic to optimists include confidence and continued effort exerted in dealing with adversity, adopting a planned and problem-focused approach particularly if the stress is controllable, the use of positive reframing and searching for benefits if the situation is uncontrollable, an acceptance of the reality of difficult situations, retaining self-control and remaining self-directed, and not focusing on distress and physical symptoms. In general optimists tend to use approach coping as compared to pessimists who tend to use avoidant coping (Carver \& Scheier, 2002). Realistic optimism involves hope and aspiration towards positive experience at the same time acknowledging what we do not, and cannot know. In periods of uncertainty, the realistic optimist will hope and work towards desired outcomes, and focus on the potential within the situational constraints (Schneider, 2001).

The Cebuano survivors had sense of coherence, as the second sign of resilience. They were able to help each other in the family and others, and the use of available resources in order to repair/rebuild damaged houses. The participants' family and significant others were helping each other and were using available materials given to them in order to rebuild damaged properties. They looked for ways like cutting woods, getting nails, reusing nails and woods that they had, borrowing materials and money. According to Antonovosky (1987, p. 19), sense of coherence is defined as a "global orientation that expresses the extent to which one has a pervasive and dynamic sense of confidence", and that we have the resources, whether human resources or material resources, available to meet the demands of difficult events, and that these demands are worthy of both the investment and the engagement. Sense of coherence encompasses the extent to which an individual perceives that they have the resources available to meet the demands as being under one's control, or under the legitimate control of others. An individual accepts that adverse events do occur but that one will be able to cope and that the consequences will be bearable. Sense of coherence includes meaningfulness, the motivational element, which relates to the position that certain areas of life are important like family and other significant others. It relates to the sense that at least some of the demands of life are worth investing in and worthy of commitment. Challenges are perceived as welcome as opposed to burdensome, and that engagement is worthwhile (Antonovosky, 1987).

The third indicator of resilience was hardiness. The participants were hardy people. They were able to take courage, remain strong, and endure the struggle moments. The participants remained strong in heart and mind for themselves and for their families. Hardiness is the ability to believe in the importance and value of who one is, the activities one is involved with, and one's involvement in life in general (Funk, 1992; Tartasky, 1993; Wiebe \& Williams, 1992). It is believed to provide a sense of purpose with which to face stressful life events, and to diminish the perceived threat in doing so. It is proposed that this can allow people to believe that they can alter the course of events and manipulate stressors. It is based within the belief that the environment is forever 
changing and that this provides opportunities for personal growth as opposed to feelings of threat and insecurity (Tartasky, 1993). Hardiness is also believed to assist the coping response through eliciting appropriate social support (Funk, 1992). Hardy individuals use more positive self-statements than others (Allred \& Smith, 1989, as cited in Tartasky, 1993); that hardiness is associated with reduced use of regressive coping, and that high hardy individuals make less threatening appraisals of stressors.

Lastly, religiosity/spirituality coping was evident in the experiences of the participants. They prayed to God, and they had faith in Him and had belief in God's mercy. These helped them cope and bounce back from their experience during the typhoon. Religiosity/spirituality has been shown to be effective in coping with disability, illness, and negative life events (Pargament, 1997). Prayer can be an effective coping mechanism (Poloma \& Pendleton, 1989). Religion and spirituality can also emerge at the points of cognitive appraisal and coping. Individuals can mobilize a variety of Religiosity/Spirituality coping strategies that can be public (e.g., religious service attendance), private (e.g., prayer) or non-traditional (e.g., meditation) in nature (Harrison, Koenig, Hays, Eme-Akwari, \& Pargament, 2001). For example, prayer functions in multiple ways (Bade \& Cook, 2008) and can be effective at many levels in dealing with crises (McCullough \& Larson, 1999). People also call on various forms of R/S support when faced with stressful events (Koenig \& Larson, 2001). They may cultivate an attachment bond with a higher power, or they may pursue spiritual connections with nature (Burkhardt, 1994) and other people such as clergy (Weaver, Koenig, \& Larson, 1997).

Practical implications can be drawn from the results of the study. Optimism is viewed as a strength in that evidence suggests that this in turn influences behaviour and coping strategies at times of challenge (Carver \& Scheier, 2002). In counseling practice and providing psychosocial support, it has been revealed that encouraging active engagement with environment, taking responsibility for one's actions, promoting proactive stance for the future, and maintaining positive expectancies about the future have greater benefits in terms of reducing distress, effectively managing difficult situations, and healthier level of psychological well-being (Carver \& Scheier, 2002). Analysis of the benefits of optimism conforms to the recommendations included in models on the nature and treatment of clinical orders such as depression and anxiety (Segal, Williams, \& Teasdale, 2002), and various other positive psychology models.

The indicator, hardiness, infers that individuals identified as hardy experience the same number of stressful life events but that the presence of hardiness diminishes their impact (Wiebe \& Williams, 1992). Hardiness is believed to assist the coping response through eliciting appropriate social support (Funk, 1992). While sense of coherence can influence the impact of trauma and can be a protective factor that may diminish or attenuate the impact of trauma on the individual (Almedon, 2005). In developing prevention and postvention programs, awareness and valuing oneself, recognition of available resources and appreciation of the presence of the significant others or support system are believed to assist successful coping with life's stresses and to attenuate anxiety and depression (Flannery, Perry, Penk \& Flannery, 1994).

The findings of the study suggest practical implications with regards to the presence of religiosity and spirituality among Cebuanos. In the practice of counseling services, counselors and clients can also benefit from the practices and principles of religion (Blando, 2006; Cornish, Wade, Tucker, \& Post, 2014). Thus, incorporating religious practices and principles in counseling for disaster survivors may help the counseling sessions more engaging and effective. The results also indicate that helping is an important part of religious Filipinos (Batara, 2015).

For the learners and teachers, the results will increase understanding of resiliency process and appreciation in identifying individuals' strengths, protective factors and capacities. Through the study of individual resiliency, they can recognize that people possess selective strengths, which are often referred to as protective factors that help them survive adversity (Richardson, 2002). The experience in successfully overcoming adverse situations increases self-efficacy and confidence in ones' ability (Kitano \& Lewis, 2005).

Overall, Cebuanos' are resilient people. Because of their sense of optimism and hardiness, sense of 
coherence, and being religious and spiritual, these helped Cebuanos bounce back from adversity. Knowing these indicators, it contributed to the better understanding of unique indicators of resiliency among Cebuanos. The results could be a basis in designing or developing program that would nurture the resilience of individuals. Counselors, psychologists, and other mental health professionals can develop interventions in counseling and therapy that would tap the intrinsic characteristics of resilience of the survivors and to individuals experiencing trauma, crisis and other significant life events. Strategies of the mental health professionals would target the building and nurturing the Cebuanos' "paglaum", "paningkamot"/"panlimbasog", "pagkamaisogon", "pagkamalig-on", "pagkama-ampoon", "pagtoo sa Ginoo", and "pagtinabangay". Local Government Units, Non-Government Agencies and other private and government agencies in Cebu could collaborate in designing and implementing programs addressing resilience building and enhancement.

\section{Conclusion}

The study's main goal was to identify the intrinsic indicators of individual resilience. Resilience had been characterized as the ability to "bounce back" and cope effectively in the face of difficulties", "bend, but not break under extreme stress", "rebound from adversities", "handle setbacks, persevere and adapt even when things go awry", "maintain equilibrium following highly aversive events" (Masten \& Reed, 2002). In this study, it tried to find out the innate or inherent capacities, traits of Cebuanos as signs of bouncing back or coping effectively amidst adversities. With the use of thematic analysis, four main themes were extracted from the responses of the eleven (11) female, adult, Cebuana survivors from Madridejos and Medellin, Cebu. The main themes were optimism, sense of coherence, hardiness, and religiosity/spirituality coping. Each main theme had its corresponding sub-themes. Being hopeful, being grateful, positive thinking, exerting efforts to stand up again, and striving hard to survive were the sub-themes of optimism. Sense of coherence was composed of helping each other and using available resources to rebuild or repair damaged houses. Hardiness was revealed through taking courage, enduring, remaining strong for self and family.

Lastly, religiosity/spirituality coping was shown through praying to God, having faith in God, and believing in God's mercy. Optimism, sense of coherence, hardiness, and religiosity/spirituality coping were revealed to be the intrinsic indicators of individual resiliency. Identifying these intrinsic indicators of resiliency among Cebuano survivors, it will provide recommendations for resiliency development program for survivors for any calamities as future studies.

\section{References}

Abad, R. G. (2001). Religion in the Philippines. Philippine Studies, 49(3), 337-367.

Andres, T. (1989). Positive Filipino values. Quezon City: New Day Publishers.

Antonovosky, A. (1987). Unravelling the mystery of health: How to manage stress and stay well. San Francisco: Jossey Bass.

Awara, M., \& Fasey, C. (2008). Is spirituality worth exploring in psychiatric out-patient clinics? Journal of Mental Health, 17(2), 183-191. http://dx.doi.org/10.1080/09638230701498390

Bade, M. K., \& Cook, S. W. (2008). Functions of Christian prayer in the coping process. Journal for the Scientific Study of Religion, 47(1), 123-133. http://dx.doi.org/10.1111/j.1468-5906.2008.00396.x

Baesler, E. M., Derlega, V. J., Winstead, B. A., \& Barbee, A. (2003). Prayer as interpersonal coping in the lives of mothers with HIV. Women and Therapy, 26(3-4), 283-295. http://dx.doi.org/10.1300/J015v26n03 07

Batara, J. B. L. (2015). Overlap of religiosity and spirituality among Filipinos and its implications towards religious prosociality. International Journal of Research Studies in Psychology, 4(3), 3-21. http://dx.doi.org/10.5861/ijrsp.2015.1090

Bergan, A., \& McConatha, J. T. (2001). Religiosity and life satisfaction. Activities, Adaptation and Aging, 24(3), 23-34. http://dx.doi.org/10.1300/J016v24n03_02

Bhui, K., King, M., Dein, S., \& O'Connor, W. (2008). Ethnicity and religious coping with mental distress. Journal of Mental Health, 17(2), 141-151. http://dx.doi.org/10.1080/09638230701498408 
Orio, T. R.

Blackburn, S. (1996). The Oxford dictionary of philosophy. New York: Oxford University Press.

Blando, J. A. (2006). Spirituality, religion, and counseling. Counseling and Human Development, $39(2), 114$.

Bonanno, G. A., Galea, S., Bucciarelli, A., \& Vlahov, D. (2006). Psychological resilience after disaster. Psychological Science, 17(3), 181-186. http://dx.doi.org/10.1111/j.1467-9280.2006.01682.x

Braun, V., \& Clarke, V. (2006). Using thematic analysis in psychology. Qualitative Research in Psychology, 3(2), 77-101. http://dx.doi.org/10.1191/1478088706qp063oa

Brotherson, S. E., \& Soderquist, J. (2002). Coping with a child's death: Spiritual issues and therapeutic implications. Journal of Family Psychotherapy, 13(1-2), 53-86. http://dx.doi.org/10.1300/J085v13n01 04

Burker, E. J., Evon, D. M., Sedway, J. A., \& Egan, T. (2005). Religious and non-religious coping in lung transplant candidates: Does adding God to the picture tell us more? Journal of Behavioral Medicine, 28(6), 513-526. http://dx.doi.org/10.1007/s10865-005-9025-4

Burkhardt, M. (1994). Becoming and connecting: Elements of spirituality for women. Holistic Nursing Practice, 8(4), 12-21. http://dx.doi.org/10.1097/00004650-199407000-00004

Carver, C. S., \& Scheier, M. F. (2002). The hopeful optimist. Psychological Inquiry, 13(4), 288-290.

Cornish, M. A., Wade, N. G., Tucker, J. R., \& Post, B. C. (2014). When religion enters the counseling group multiculturalism, group processes, and social justice. The Counseling Psychologist, 42(5), 578-600. http://dx.doi.org/10.1177/0011000014527001

Estanislao, S. (2001). Development of a tool to assess suicide potential among Filipino youth. Philippine Journal of Psychology, 34(1), 77-110.

Fernando, D. M., \& Hebert, B. B. (2011). Resiliency and recovery: Lessons from the Asian tsunami and hurricane Katrina. Journal of Multicultural Counseling and Development, 39(1), 2-13. http://dx.doi.org/10.1002/j.2161-1912.2011.tb00135.x

Ferraro, K. F., \& Koch, J. R. (1994). Religion and health among black and white adults: Examining social support and consolation. Journal for the Scientific Study of Religion, 33(4), 362-375. http://dx.doi.org/10.2307/1386495

Frankenhoff, C. (1998). Antonovosky's sense of coherence concept: An instrument for primary prevention in social work services. International Social Work, 41, 511-522. http://dx.doi.org/10.1177/002087289804100410

Funk, S.C. (1992). Hardiness: A review of theory and research. Health Psychology, 11(5), 335-345. http://dx.doi.org/10.1037/0278-6133.11.5.335

Gillum, T. L., Sullivan, C. M., \& Bybee, D. I. (2006). The importance of spirituality in the lives of domestic violence survivors. Violence Against Women, 12(3), 240-250. http://dx.doi.org/10.1177/1077801206286224

Gordon, P. A., Feldman, D., Crose, R., Schoen, E., Griffing, G., \& Shankar, J. (2002). The role of religious beliefs in coping with chronic illness. Counseling and Values, 46(3), 162-174. http://dx.doi.org/10.1002/j.2161-007X.2002.tb00210.X

Harrison, O., Koenig, H.G., Hays, J. C., Eme-Akwari, A. G., \& Pargament, K. I. (2001). The epidemiology of religious coping: A review of recent literature. International Review of Psychiatry, 13(2), 86-93. http://dx.doi.org/10.1080/09540260120037317

Hill, P. C., Pargament, K. I., Hood, R. W. Jr., McCullough, M. E., Swyers, J. P., Larson, D. B., \& Zinnbauer, B. J. (2000). Conceptualizing religion and spirituality: Points of commonality, points of departure. Journal for the Theory of Social Behaviour, 30, 51-77. http://dx.doi.org/10.1111/1468-5914.00119

Jennings, B. M., \& Staggers, N. (1994). A critical analysis of hardiness. Nursing Research, 43(5), $274-281$. http://dx.doi.org/10.1097/00006199-199409000-00004

Johnstone, B., Glass, B. A., \& Oliver, R. E. (2007). Religion and disability: Clinical, research and training considerations for rehabilitation professionals. Disability and rehabilitation, 29(15), 1153-1163. http://dx.doi.org/10.1080/09638280600955693

Khanlou, N., \& Wray, R. (2010). Resilience and the promotion of protective factors among children and youth: Review of concepts, promising practices and public health roles in mental health promotion. Ottawa: 
Public Health Agency of Canada.

Kirby, L. D., \& Fraser, M. W. (1997) Risk and resilience in childhood: An ecological perspective. Washington, DC: NASW Press.

Kitano, M. K., \& Lewis, R. B. (2005). Resilience and coping: Implications for gifted children and youth at risk. Roeper Review, 27(4), 200-205. http://dx.doi.org/10.1080/02783190509554319

Koenig, H. G., \& Larson, D. B. (2001). Religion and mental health: Evidence for an association. International Review of Psychiatry, 13(2), 67-78. http://dx.doi.org/10.1080/09540260124661

LaPierre, L. L. (1994). A model for describing spirituality. Journal of Religion and Health, 33, 153-161. http://dx.doi.org/10.1007/BF02354535

Levin, J. S., Taylor, R. J., \& Chatters, L. M. (1994). Race and gender differences in religiosity among older adults: Findings from four national surveys. Journal of Gerontology, 49(3), 137-145. http://dx.doi.org/10.1093/geronj/49.3.S137

Luthar, S. S., Cicchetti, D., \& Becker, B. (2000). The construct of resilience: A critical evaluation and guidelines for future work. Child Development, 71(3), 543-562. http://dx.doi.org/10.1111/1467-8624.00164

Marler, P. L., \& Hadaway, C. K. (2002). "Being religious" or "being spiritual" in America: A zero-sum proposition? Journal for the Scientific Study of Religion, 41(2), 289-300. http://dx.doi.org/10.1111/1468-5906.00117

Masten, A. \& Reed, M. (2002). Resilience in development. In C.R. Synder \& S.J. Lopez (Eds.), Handbook of positive psychology (pp. 74-88). NY: Oxford University Press.

Masten, A. S. (2001). Ordinary magic: Resilience processes in development. American Psychologist, 56(3), 227-238. http://dx.doi.org/10.1037/0003-066X.56.3.227

Masten, A. S., \& Powell, J. L. (2003). A resilience framework for research, policy, and practice. In S. S. Luthar (Ed.), Resilience and vulnerability: Adaptation in the context of childhood adversities (pp. 1-25). New York, NY: Cambridge University Press. http://dx.doi.org/10.1017/CBO9780511615788.003

Mattis, J. (2004). Spirituality and Religion in African American life. In R.L. Jones (Ed.), Black Psychology (4 ${ }^{\text {th }}$ ed., pp. 93-115). Hampton, VA: Cobb \& Henry Publishers.

McCullough, M. E., \& Larson, D. B. (1999). Religion and depression: a review of the literature. Twin Research, 2(2), 126-136. http://dx.doi.org/10.1375/136905299320565997

Meisenhelder, J. B., \& Marcum, J. P. (2004). Responses of clergy to 9/11: Posttraumatic stress, coping, and religious outcomes. Journal for the Scientific Study of Religion, 43(4), 547-554. http://dx.doi.org/10.1111/j.1468-5906.2004.00255.x

Oman, D., \& Reed, D. (1998). Religion and mortality among the community-dwelling elderly. American Journal of Public Health, 88(10), 1469-1475. http://dx.doi.org/10.2105/AJPH.88.10.1469

Pargament, K. I. (1997). The psychology of religion and coping: Theory, research, practice. New York: Guilford Press.

Pargament, K. I. (1999). The psychology of religion and spirituality? Yes and no. International Journal for the Psychology of Religion, 9, 3-16. http://dx.doi.org/10.1207/s15327582ijpr0901_2

Pollock, S. E. (1989). The hardiness characteristic: A motivating factor in adaptation. Advances in Nursing Science, 11(2), 53-62. http://dx.doi.org/10.1097/00012272-198901000-00009

Poloma, M. M., \& Pendleton, B. F. (1989). Exploring types of prayer and quality of life: A research note. Review of Religious Research, 31(1), 46-53. http://dx.doi.org/10.2307/3511023

Renschler, C. S., Frazier, A. E., Arendt, L. A., Cimellaro, G. P., Reinhorn, A. M., \& Bruneau, M. (2010, July). Developing the 'PEOPLES' resilience framework for defining and measuring disaster resilience at the community scale. In Proceedings of the 9th US national and 10th Canadian conference on earthquake engineering (9USN/10CCEE), Toronto (pp. 25-29).

Richardson, G. E. (2002). The metatheory of resilience and resiliency. Journal of Clinical Psychology, 58(3), 307-321. http://dx.doi.org/10.1002/jclp.10020

Roff, L. L., Durkin, D., Sun, F., \& Klemmack, D. L. (2007). Widowhood, religiousness, and self-assessed well-being among older adults. Journal of Religion, Spirituality and Aging, 19(4), 43-59.

http://dx.doi.org/10.1300/J496v19n04_04 
Orio, T. R.

Rose, A. Z. (2009). Economic resilience to disasters. Retrieved from http://research.create.usc.edu/cgi/viewcontent.cgi?article $=1015 \&$ context=published papers

Schneider, S. L. (2001). In search of realistic optimism: Meaning, knowledge and warm fuzziness. American Psychologist, 56(3), 250-263. http://dx.doi.org/10.1037/0003-066X.56.3.250

Spilka, B. (1993, August). Spirituality: Problems and directions in operationalizing a fuzzy concept. Paper presented at the American Psychological Association annual conference, Toronto, Canada.

Stifoss-Hanssen, H. (1999). Religion and spirituality: What a European ear hears. The International Journal for the Psychology of Religion, 9(1), 25-33. http://dx.doi.org/10.1207/s15327582ijpr0901_4

Tartasky, D. S. (1993). Hardiness: Conceptual and methodological issues. Journal of Nursing Scholarship, 25(3), 225-229. http://dx.doi.org/10.1111/j.1547-5069.1993.tb00786.x

Taylor, R. J. Chatters, L.M., \& Levin, J. (2004). Religion in the lives of African Americans: Social, psychological and health perspectives. Thousand Oaks, CA: Sage.

The World Federation. (2014). Philippines typhoon appeal report. Retrieved from https://www.worldfederation.org/sites/default/files/uploaded_files/Philippines\%20Typhoon\%20Haiyan $\%$ 20Report.pdf

Thompson, M. P., \& Vardaman, P. J. (1997). The role of religion in coping with the loss of a family member to homicide. Journal for the Scientific Study of Religion, 36(1), 44-51. http://dx.doi.org/10.2307/1387881

Utsey, S. O., Bolden, M. A., Lanier, Y., \& Williams, O. (2007). Examining the role of culture-specific coping as a predictor of resilient outcomes in African Americans from high-risk urban communities. Journal of Black Psychology, 33(1), 75-93. http://dx.doi.org/10.1177/0095798406295094

Utsey, S.O., Adams, E.P., \& Boldn, M.A. (2000). Developmental and initial validation of the Africultural Coping System Inventory. Journal of Black Psychology, 26, 194-215. http://dx.doi.org/10.1177/0095798400026002005

Weaver, A. J., Koenig, H. G., \& Larson, D. B. (1997). Marriage and family therapists and the clergy: A need for clinical collaboration, training, and research. Journal for Marital and Family Therapy, 23(1), 13-25. http://dx.doi.org/10.1111/j.1752-0606.1997.tb00228.x

Wiebe, D. J. \& Williams, P. G. (1992). Hardiness and health: A social psychophysiology perspective on stress and adaptation. Journal of Social and Clinical Psychology, 11(3), 238-262. http://dx.doi.org/10.1521/jscp.1992.11.3.238

Williams, P. G., Wiebe, D. J. \& Smith, T. W. (1992). Coping processes as mediators of the relationship between hardiness and health. Journal of Behavioural Medicine, 15(3), 227-255. http://dx.doi.org/10.1007/BF00845354

Wulff, D. M. (1997). Psychology of religion: Classic and contemporary (2nd ed.). New York: Wiley \& Sons. 